\title{
La manifestación de la experiencia en las unidades hoteleras. Un análisis de los comentarios a hoteles en Machu Picchu en la red TripAdvisor
}

\section{Manifestation experiences in hotel units. An analysis of Machu Picchu's hotels reviews on TripAdvisor network}

Recibido: 01/04/2020

Aceptado: 15/06/2020

Publicado: 26/06/2020
Andreia Galhardo galhardo@ufp.edu.pt https://orcid.org/0000-0002-4959-8002 Universidade Fernando Pessoa (Portugal)

Álvaro Cairrão acairrao@esce.ipvc https://orcid.org/0000-0002-1172-7884 Instituto Politécnico de Viana do Castelo Centro de Estudos de Comunicação e Sociedade Instituto de Ciências Sociais, Universidade do Minho (Portugal)

Resumen: El presente artículo describe la imagen de los hoteles transmitida por los clientes en la red social TripAdvisor.es. Se trata de un estudio de caso que descompone e interpreta el análisis de un conjunto de comentarios, en la lengua castellana, acerca de 20 hoteles en Machu Picchu (Perú). Asimismo, se realizó un análisis descriptivo, basado en la inferencia de datos cualitativos y cuantitativos, a 177 comentarios de la red social mencionada, distribuidos en los primeros 20 hoteles de la lista de clasificación del viajero, entre los meses de octubre y diciembre de 2019. Los comentarios fueron analizados a 
través de una tabla compuesta por 14 categorías, observándose la prevalencia de comentarios positivos en todas las categorías y que las experiencias más apreciadas por los viajeros (y descritas en nuestra muestra) fueron "servicio", "comida" y "ubicación".

Palabras clave: Hoteles, Redes sociales, TripAdvisor, Imagen, Reputación.

Abstract: This paper describes the image of hotels transmitted by customers on the social network TripAdvisor.es. It is a case study that breaks down and interprets the analysis of a set of comments in the Spanish language to 20 hotels in Machu Picchu (Peru). Moreover, we did a descriptive analysis, based on the inference of qualitative and quantitative data, to 177 comments of the aforementioned social network, distributed by the first 20 hotels listed in order of classification of the traveler, between the months October to December 2019. The comments were analyzed through a table composed of 14 categories and we observed that positive commentaries prevail in all categories, and that the experiences most appreciated by travelers and described in our sample were "Service", "Food", and "Location".

Key words: Hotels, Social media, TripAdvisor, Image, Reputation.

\section{Introducción}

Esta investigación se ancla en el siguiente objetivo general: determinar qué imagen transmiten los huéspedes en la red social TripAdvisor.es de los hoteles ubicados en Machu Picchu. Para lograr dicha meta, se plantearon los siguientes objetivos específicos:

- Identificar qué atributos de experiencia informan los huéspedes en la red social TripAdvisor.es de los hoteles de Machu Picchu que se verifican con mayor frecuencia.

- Verificar si la mayoría de los comentarios de los huéspedes en la red social TripAdvisor.es de los hoteles de Machu Picchu hacen referencia a experiencias positivas o negativas. 
Entendemos, en este trabajo, el comentario o revisión online como "una forma de boca-a-boca electrónica (e-WOM) que se refiere a los contenidos generados por el usuario que se publican en sitios web de proveedores electrónicos o sitios web de terceros"1 (Mudambi \& Schuff, citados en Bui, 2017, p. 16).

\section{Turismo 2.0: mudanzas en la comunicación y en los procesos de decisión}

En el turismo 2.0, los procesos de comunicación y toma de decisiones han cambiado y se ha entrado en una nueva fase, caracterizada por la transparencia, por la desaparición gradual de los intermediarios y por la cooperación entre viajeros (Cohen \& Olsen, 2013; Galhardo, 2017; Li et al., 2015; Lei \& Law, 2015). De acuerdo con Majó et al. (2018),

Las nuevas tecnologías, afectan el conocimiento, las actitudes y el comportamiento de los turistas, debido a la transparencia que hay tanto de precios como de productos, esto hace que aumente el poder de los viajeros, que cada día son más sensibles a los precios, menos leales a la marca y más sofisticados. (p. 150)

En la era de la transparencia, siempre hay alguien (en algún lugar virtual, en alguna comunidad) que habla sobre la marca, los productos y los precios. Estar en la web ya no es una opción para las marcas, sino estar expuesto en una dimensión nunca antes pensada. Este hecho requiere que las marcas adopten políticas claras de transparencia, porque una mentira podrá destruir toda la reputación que la marca ha logrado en el mercado. Como se mencionó anteriormente, la web 2.0 está a punto de terminar con los intermediarios del sector turístico:

A este respecto, por ejemplo, el peso de la opinión de otros usuarios/ clientes sustituye, en gran medida, al papel de la agencia de viajes tradicional. Una opinión leída en redes sociales, como TripAdvisor o Facebook, es importante para el turista porque fue emitida por alguien

1. "A form of electronic word of mouth (eWOM) that refers to the user-generated contents that are posted on e-vendor websites or third-party websites" (texto original en inglés). 
que ya ha pasado por la vivencia del consumidor que quiere experimentar. Las imágenes que se publican en Instagram reemplazan a las imágenes tradicionales de los catálogos de viajes. El usuario busca en la página de Facebook del hotel para ver sus imágenes o el destino turístico y consulta a sus websites para obtener información sobre espacios, condiciones, posibles promociones, entre otros. ${ }^{2}$ (Galhardo, 2017, p. 370).

Los cambios globales introducidos por las tecnologías de la información y la difusión de las redes se extienden a la comunicación y nos llevan a lo que llamamos "cooperación entre viajeros". Es importante recordar la importancia de la comunicación boca-a-boca en los procesos de toma de decisiones, basada en la confianza que el consumidor siente hacia el parecer de otros consumidores y que es superior a la que tiene sobre la publicidad o promotores de marca. El e-WOM es la extensión electrónica y viral del boca-a-boca:

De esta manera, las plataformas que los usuarios de Internet crean y nutren son vehículos muy importantes para e-WOW:

El usuario de la web 2.0 es el turista 2.0, un individuo activo y proactivo, receptor y emisor de la comunicación: busca y genera información, tiene los medios y conocimientos para llevar a cabo la investigación que necesita y las habilidades y plataformas para difundir opiniones e información. ${ }^{3}$ (Galhardo, 2017, p. 370)

Por cooperación entre consumidores entendemos el acto de compartir, la acción de distribuir o difundir a otros, a través de plataformas online, las

2. "Neste aspeto, por exemplo, o peso da opinião de outros usuários/ clientes vem substituir em grande parte o papel d o tradicional agente de viagens. Uma opinião lida num media social como o TripAdvisor ou o Facebook é importante para o turista por ter sido emitida por alguém que já vivenciou a experiência de consumo que o mesmo pretende vivenciar. Imagens que são divulgadas no Instagram substituem as tradicionais imagens dos catálogos de viagens. O usuário procura no Facebook do hotel visualizar imagens de um estabelecimento hoteleiro ou destino turístico e consulta os respetivos wesbites para obter informações sobre os espaços, as condições, eventuais promoções, entre outras" (texto original en portugués).

3. "O usuário da web 2.0 é o turista 2.0, um indivíduo ativo e proativo, recetor e emissor da comunicação: procura e gera informação, tem os meios e conhecimento para realizar as pesquisas de que necessita e as competências e plataformas para difundir opiniões e informações" (texto original en portugués). 
experiencias positivas o negativas con respecto al consumo de diferentes productos y servicios. Así, los viajeros revisan constantemente plataformas especializadas como TripAdvisor, que es nuestro objeto de estudio. Dicha plataforma de viajes es la más grande y extendida del mundo. Según su sitio web oficial,

ayuda a 460 millones de viajeros cada mes a hacer de su viaje el mejor. Los viajeros de todo el mundo utilizan la web y la aplicación de TripAdvisor para consultar más de 830 millones de comentarios y opiniones de 8,6 millones de alojamientos, restaurantes, experiencias, vuelos y cruceros ... TripAdvisor, el mejor compañero de viaje, está disponible en 49 mercados y 28 idiomas. (TripAdvisor, 2020)

Este compañero de viaje coopera con sus usuarios, tal como lo hiciera un amigo: en este caso, comparar precios de hoteles, vuelos y (lo que más interesa en este trabajo) compartir experiencias, a través de comentarios y clasificaciones que están inscritos en una experiencia de consumo de un determinado hotel. Así se constituyen percepciones y representaciones que componen la imagen de una entidad, es decir, el conjunto de figuras mentales que el público tiene sobre cada marca. Es precisamente esta imagen mental la que tiene un peso significativo en la notoriedad de las empresas, es decir, en su reconocimiento general, en su reputación.

En un escenario como el del TripAdvisor, los gerentes de hotel tienen que analizar tanto las opiniones negativas como positivas que revelan sus huéspedes, a fin de atender las debilidades, mejorar su servicio y reforzar lo que ya se ha reconocido como puntos meritorios de la oferta. En resumen, la web 2.0. puede ayudar a comprender mejor los procesos de decisión, en constante cambio.

\subsection{La reputación online: el impacto de los comentarios online para las empresas}

La presencia de marcas en el entorno online (ya sea en sitios web, redes sociales, blogs, u otras plataformas) crea una cierta imagen de ellas mismas, llamada "reputación online": es la presencia distintiva y múltiple dentro del mundo virtual que se están formando en las mentes de los agentes del mercado, voluntaria e involuntariamente. La reputación se construye voluntariamente mediante plataformas que las empresas controlan, como es el caso de sus sitios web; e 
involuntariamente en otros sitios web, cuyo contenido excede el margen de control de las empresas. Es en el último caso donde encontramos los comentarios publicados por los clientes y que inciden en la opinión de otros clientes.

El impacto de los comentarios online (sobre todo los de la plataforma TripAdvisor) se han estudiado en varias encuestas, reseñándose el denominado "efecto TripAdvisor", vinculado al cambio de hoteles en la provisión de servicios, el efecto en las ganancias de las unidades hoteleras y las ventajas para los viajeros.

Algunos estudios muestran que las críticas en las redes sociales contribuyen a un cambio en la provisión de los servicios: "Las redes sociales y las tecnologías de la información y la comunicación (TIC) han revolucionado el sector hotelero, modificando las actividades comerciales y la forma de promocionar sus servicios" (Cohen \& Olsen, citados en Majó et al., 2018, p. 150). Estos cambios (hacia una mayor satisfacción del cliente, lo que implica una reducción de factores débiles en el servicio) se deben, en parte, a los comentarios que las empresas obtienen fácilmente de sus clientes, ya que estos comentarios están disponibles para cualquier gerente a través de Internet, teniendo un fuerte impacto en la postura y el rendimiento de los hoteles y, en consecuencia, en sus ingresos.

Cunningham et al. (2010) estudiaron el efecto TripAdvisor, comparando una muestra del sector hotelero irlandés con una muestra de hoteles en Los Ángeles, concluyendo que (en relación con este último) la conexión entre las críticas de la red social, la respuesta de estas y las mejoras en las prácticas hoteleras no es algo que esté perfectamente instituido. Por el contrario, en el sector irlandés (donde el volumen de comentarios en TripAdvisor entre 2007 y 2009 aumentó considerablemente) parece que el efecto TripAdvisor fue notable: los hoteles son sensibles a las opiniones de los huéspedes que dicen exactamente qué aspectos del servicio deben ser mejorados: que "al menos algunas de las mejoras se correlacionan con un aumento de la conciencia de TripAdivsor entre los gerentes de hoteles, lo que conduce a una mejora genuina en la calidad del servicio"4 (Cunningham et al., 2010, p. 10).

4. "At least some of the improvement correlates with an increase awareness of TripAdivsor among hotel managers leading to a genuine improvement in product quality" (texto original en inglés). 
Majó et al. (2018) estudiaron las evaluaciones de los hoteles en las redes sociales y cómo se relacionan con sus ingresos. Estudiaron, específicamente, datos que se refieren a 48 hoteles sudamericanos (ubicados en Ecuador, Perú y Colombia), en el período comprendido entre agosto de 2014 y julio de 2015, determinándose que un mejor Global Review Index conduce a una mejor relación entre ventas y oferta (p. 148). También Diana-Jens \& Rodríguez (2015) demuestran claramente que la reputación online tiene impacto en la política de precios de los hoteles:

Un establecimiento situado en la primera posición de un destino, aparte de tener mayor visibilidad y, por lo tanto, posibilidades de compra por parte del consumidor, establece de media sus precios un $22,26 \%$ más alto que los precios de su set de competidores para un mismo tipo de producto. (p. 36)

Yi et al. (2018) han argumentado que las experiencias reportadas en las revisiones online de hoteles siempre afectan la rentabilidad de las empresas y pueden aumentar o disminuir la reputación de una marca (p. 193). Existen varias estrategias para aumentar la clasificación de las empresas en TripAdvisor:

- Garantizar que se ofrezca un servicio memorable, lo que potencia el registro de una opinión positiva.

- Imaginar las historias que les gustaría leer en los comentarios y llevar a todo el equipo del hotel a trabajar para que esto suceda.

- Ser honesto y no ocultar debilidades ni, exageradamente, demuestre los puntos fuertes con el fin de publicar comentarios positivos.

- Involucrar a todo el equipo haciéndolo participar en los comentarios en los que se menciona añadiéndole valor. (ReviewPro, 2013)

En un comentario sobre esta última estrategia, Majó et al. (2018) afirman que:

Los hoteles que reciben los mejores comentarios son generosos con los extras, como el acceso a wi-fi, desayuno, upgrades o bebidas de cortesía. Cuando toman estas decisiones los hoteles, las incluyen en el rubro de gastos que conllevan un beneficio en su reputación online. (p.152)

Asimismo, existen estrategias destacadas como la "actitud positiva" y apasionada del personal que trata a los clientes; invertir en la hospitalidad tradi- 
cional, identificando y satisfaciendo las necesidades particulares de los huéspedes y abordar los problemas que surgen, evitando que se conviertan en críticas negativas online (ReviewPro 2013).

\subsection{Reputación online: el impacto de los comentarios para los consumi- dores}

Cabe señalar que la intangibilidad (que caracteriza el sector de los servicios y que impide que sean evaluados antes del consumo) explica la importancia de las opiniones de otros viajeros al tener que elegir un hotel o un paquete de vacaciones. Ya sea que los comentarios del sector turístico tengan un papel informativo o de recomendación, también son de gran relevancia, puesto que se relacionan con compras que implican algún riesgo financiero y, por asociación, una participación más marcada del cliente: "Dado que viajar es un producto de alta participación, se puede esperar un uso extensivo de las revisiones para las decisiones relacionadas con los viajes"5 (Gretzel \& Yoo, 2008, p. 37).

Los comentarios online tienen un fuerte impacto en los consumidores, ya que son percibidos como información independiente, producida por aquellos que han experimentado un servicio determinado. Así, dichos comentarios (desde la perspectiva del consumidor) brindan la oportunidad de una experiencia indirecta (Bickart \& Schindler, citados en Gretzel \& Yoo, 2008, p. 37).

Al ser generador por los propios consumidores, estos comentarios son percibidos como información gratuita y desinteresada, en lugar de las comunicaciones promocionales, posicionándose así en lo que ya hemos llamado "cooperación entre viajeros". Flores \& Tijero (2017) realizaron una encuesta con el objetivo principal de determinar cómo la usabilidad de TripAdvisor afecta la demanda de hoteles de 3 estrellas en el Centro Histórico del Cusco. Los autores concluyeron que "el $87,5 \%$ de los usuarios encuestados de TripAdvisor consideran que leer opiniones es importante a la hora de reservar hoteles y el $66,7 \%$ de estos usuarios dicen que no reservarían un hotel que no tiene comentarios dentro de la página" (p. xxi).

5. "Since travel is a high involvement product, one can expect extensive use of reviews for travel-related decisions" (texto original en inglés). 
Cuando se trata de elegir un hotel, los viajeros confían principalmente en la opinión de sus pares: este conjunto de referencias y testimonios forman la base sobre la cual se construye la reputación online de las empresas: la construcción social alrededor de la credibilidad, fiabilidad, moralidad y coherencia que se tiene de una persona, ente, organismo, institución o empresa, etc. Por ello solo es parcialmente controlable por el sujeto, ya que se crea y recrea a partir de las percepciones que conforman un estado de opinión, consideración y valoración de otros. (Del Fresno, citado en Majó et al., 2018, p. 151)

El impacto de estas opiniones y referencias encontradas en diferentes plataformas online no solo tienen efecto en el momento de la colecta de datos o de la planificación inicial de un viaje. Gretzel \& Yoo (2008) estudiaron el uso y el impacto de los comentarios online en diferentes momentos del viaje, desde la planificación hasta el viaje posterior, a través de un cuestionario a 1480 usuarios de la red social de TripAdvisor. El estudio reveló que el mayor uso de los comentarios online se realiza durante el proceso de planificación de viajes (para limitar las opciones), pero que es muy importante al principio de la misma. Además,

las opiniones en línea de otros viajeros también son importantes en etapas posteriores para confirmar las decisiones. Casi el $41 \%$ de los lectores de reseñas de viajes los utilizan en esta etapa. Curiosamente, casi un tercio $(29,5 \%)$ de los lectores de revisión de viajes, las críticas también son importantes en la fase de post-consumo para comparar notas con otros y compartir experiencias. Solo el $8,7 \%$ utiliza opiniones para informar las decisiones durante un viaje. ${ }^{6}$ (Gretzel \& Yoo 2008, p. 40)

Además, el mencionado estudio revela que los lectores perciben varias ventajas en los comentarios, tales como información actualizada, información interesante y confiable, información detallada y relevante (Gretzel \& Yoo, 2008, p. 40). Si los comentarios positivos (junto con las calificaciones numéricas) tienden a aumentar las intenciones de reserva y la confianza, es la informa-

6. “Other travelers' online reviews are also important in later stages to confirm decisions. Almost 41 percent of travel review readers use them in this stage. Interestingly, for almost a third (29.5\%) of the travel review readers, reviews are also important in the postconsumption phase to compare notes with others and share experiences. Only 8.7 percent use reviews to inform decisions during a trip" (texto original en inglés). 
ción negativa la que más influye en los consumidores, especialmente cuando tienen esa indicación (Sparks \& Browning, 2011).

Los comentarios en las redes sociales son, en resumen, de interés diverso, útiles en diferentes momentos de viaje y se configuran como un grupo de impresiones vívidas que contribuyen a la creación de la reputación online de las marcas. Dicha reputación hace que los responsables de las empresas definan estrategias en el universo competitivo que es el comercio y la comunicación en Internet.

\section{Metodología}

La complejidad en la búsqueda del conocimiento científico obliga a los investigadores a obedecer un conjunto de métodos y procedimientos como un diferencial para explicar un conjunto de fenómenos. Según Lakatos \& Marconi (2007), "la investigación es un procedimiento formal, con un método de pensamiento reflexivo, que requiere tratamiento científico y constituye la forma de conocer la realidad o descubrir verdades parciales"》 (p. 15).

Para responder a las expectativas de este trabajo, clasificamos la presente investigación como exploratoria y descriptiva, ya que está destinada no sólo a estudiar y comprender un fenómeno, sino también a analizar los comentarios de los clientes de los hoteles ubicados en Machu Picchu para determinar la imagen y la reputación de los mismos transmitidos en las redes sociales. En este sentido, se procedió a un análisis de contenido (de naturaleza temática) sobre un conjunto de comentarios publicados por viajeros en la red de TripAdvisor. Esta enigmática ciudadela inca del siglo XV (situada en una meseta alta, famosa por su arquitectura y las vistas que ofrece) es Patrimonio Cultural y Natural de la Humanidad, así como la principal atracción turística del Perú.

La muestra se construyó por conveniencia, buscando los términos "hoteles + Machu Picchu" y con base en el criterio "clasificación del viajero", en la red

7. "A pesquisa é um procedimento formal, com método de pensamento reflexivo, que requer um tratamento científico e constitui-se no caminho para se conhecer a realidade ou para descobrir verdades parciais" (texto original en portugués). 
social referida. En esta investigación se eligieron los primeros 20 hoteles en la lista de preferencias. Asimismo, se seleccionaron los comentarios realizados entre octubre y diciembre de 2019, alcanzando un total de 177, un número que constituye nuestra muestra. Los datos fueron recolectados el 1 y 2 de febrero de 2020.

El contenido de los comentarios se clasificó en función de los atributos de experiencia informados, y se encontraron 14 cualidades diferentes, que formaron nuestra tabla de análisis. Se determinó si las cualidades se evaluaron positiva o negativamente y también se trató de entender si los huéspedes recomiendan (o no) las unidades del hotel a través de una expresión clara e indudable.

\section{Resultados}

Del análisis de contenido a los 177 comentarios, extrajimos 14 categorías, a saber, atributos o cualidades de experiencia que el huésped tuvo durante su estadía en el hotel: "servicio", "impresión general", "habitación", "baño", "limpieza", "instalaciones", "comida", "estética", "ubicación", "precio", "costo-beneficio", "ofertas", "spa” y "ecología".

\section{Figura 1}

\section{Experiencias positivas}

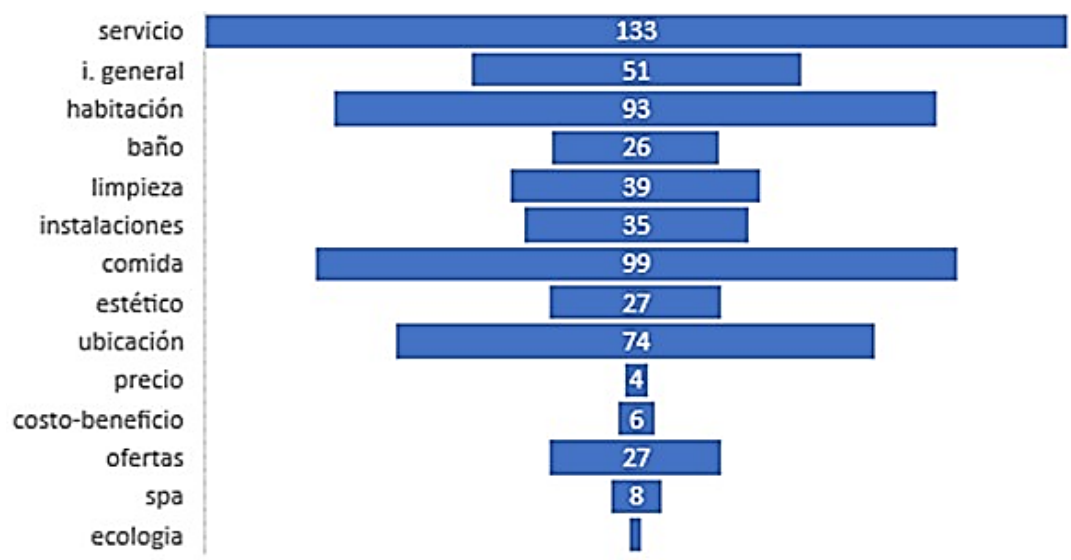

Nota: Elaboración propia.

Dichas categorías (ver Figuras 1 y 2) fueron evaluadas dentro de perspectivas tanto negativas como positivas. 


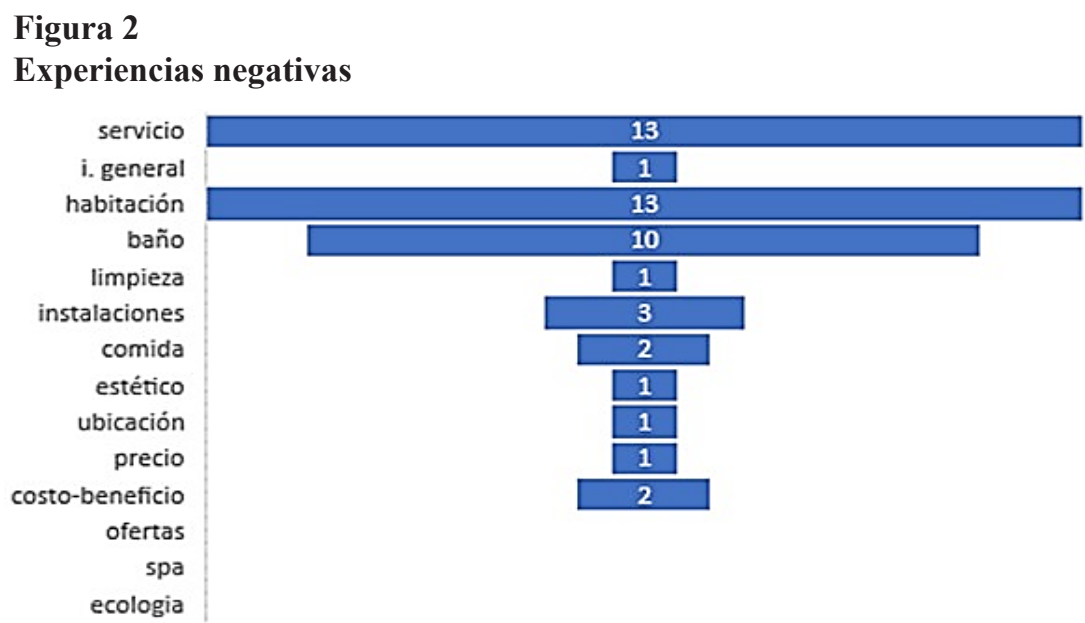

Nota: Elaboración propia.

\subsection{Servicio}

En la primera categoría incluimos las partes de los comentarios que destacan la experiencia genérica del servicio, la amabilidad o disponibilidad de los empleados, la eficiencia y la eficacia del servicio. De los 146 comentarios que se refieren al servicio, la abrumadora mayoría (91\%) lo hace de manera positiva y solo el $8,9 \%$ de los huéspedes alude a las debilidades atribuidas a esta experiencia. Por ejemplo, podemos destacar expresiones positivas como: “¡La atención no pudo ser mejor!”, “¡El trato del personal es de primera!”, "El personal muy atento y amable te hacen sentir como en casa". Una mala experiencia llevó a un viajero a escribir: "Tuve que pagar 25 dólares por salir más tarde. No lo veo correcto", lo que muestra insatisfacción con el servicio global del hotel.

\subsection{Impresión general}

En la segunda categoría se incluyeron comentarios referidos a la experiencia como un todo, figurando generalmente en forma de título, en la primera oración del texto. Lo que está en juego en este apartado no es un aspecto particular del hotel o la estadía, sino la idea genérica que se comunica. Cabe señalar que la mitad de la muestra (52\%) destaca esta variable, extensivamente en casi todos los comentarios positivos (98\%), dejando solo el $2 \%$ para una ex- 
presión de negatividad. Podemos ejemplificar los favorables con expresiones como: "Por lo general todo estuvo muy bien” y "¡Muy buen hotel!". Los negativos aparecen en declaraciones como "No tiene la categoría de un 4 estrellas" y "Vergonzoso".

\subsection{Habitación}

En estos comentarios, el huésped hace una descripción crítica de las habitaciones, sus comodidades, la calidad del sueño, los espacios, la decoración, entre otros. Es la tercera experiencia más comentada, después del servicio y la comida. En total, el $60 \%$ de las personas incluyen la habitación en sus observaciones, en el $87,7 \%$ de los casos son positivos y en el $12,3 \%$, negativos. Los ejemplos ilustrativos de las dos ocurrencias son los siguientes: "Camas y almohadas muy cómodas", "Habitaciones amplias y muy lindas”, " ¡Habitaciones con vista al rio, un sueño!", "Belleza de habitación con jacuzzi", "Hay que mejorar la insonorización" o "Entra el humo de la locomotora por la ventana".

\subsection{Baño}

Los comentarios en esta categoría aluden a diferentes experiencias como la calidad del baño, el tamaño del espacio y la limpieza, y representa en nuestra muestra el 20,3\%. De estos comentarios, el $72 \%$ son de naturaleza positiva y el $28 \%$ de naturaleza negativa. En este último caso, se presenta la siguiente queja: "Al día siguiente no había agua, no avisaron y no tenían prevención. Tuve que ir a comprar agua mineral para bañarme". También en un registro negativo, pero sin el tono de denuncia, se lee el comentario: "Bueno, detalles en tamaño del baño". Las experiencias positivas se expresan en comentarios como: "Un baño grande, cómodo" o "La ducha del baño es espectacular".

\subsection{Limpieza}

Sólo el 24\% de los comentarios hace alusión a esta categoría. Para la limpieza nos referimos a expresiones que apuntan a la higiene de los diferentes espacios del hotel. El 92,8\% de los clientes comenta positivamente este aspecto, en expresiones como: "Habitaciones limpias" o "Súper limpio". Las valora- 
ciones negativas representan el 24\% de los comentarios: "La limpieza de las habitaciones es mala, muy mala, no recogen las bandejas de los servicios de comida a la habitación, no sacan la basura..."

\subsection{Instalaciones}

En esta categoría, insertamos referencias a las características de los espacios comunes de las diferentes áreas del hotel, su modernidad o confort, así como las vistas proporcionadas por los edificios. Estos son temas con apenas el 21,5\% de los comentarios, con mayor frecuencia en un tono positivo $(92,1 \%)$, con solo el $7,9 \%$ de las ocurrencias negativas. De estos últimos, se subraya una queja relativa al ruido: "Los días que nos tocó estar, el hotel fue muy ruidoso". Como dijimos, las experiencias son (en su mayoría) positivas, comentando experiencias como las siguientes: "Las instalaciones hermosas", "Instalaciones nuevas y en perfecto estado", "Ideal que tenga ascensor para la tercera edad", "Wi-fi excelente" o "Tiene espacios con plantas y lugares para estar muy agradables".

\subsection{Comida}

La categoría de alimentos remite a comentarios que subrayan la calidad, cantidad y variedad de esta experiencia, así como la conveniencia de las horas en que se prestan los servicios. Es, después del "servicio", la experiencia más reportada, con un $57 \%$. Casi todos los comentarios son positivos, con un 98\%. En cambio, se registra un 2\% de opiniones disidentes, que incluyen: "El desayuno, quizás por la hora, no había mucha variedad". La mayoría de los clientes informan experiencias positivas como: "El restaurante del hotel es muy bueno al igual que el desayuno", "El desayuno exquisito, la comida y la cena muy rica", "Y ni qué decir de su espectacular y contundente desayuno" o, aún, "Tenían de todo y buenísimo, calidad suprema, gran surtido, tipos diferentes de leches (soja, avena...) embutidos, dulces".

\subsection{Estético}

Esta categoría alude a la apariencia del hotel, su belleza, la estética de los detalles, el entorno $y$, curiosamente, es una experiencia más común que la 
del "baño", brindando críticas positivas. Encontramos en la muestra 28 comentarios sobre la estética de las unidades hoteleras (15,8\%), el 96,4\% de los cuales se refieren a experiencias positivas, mientras que solo el 3,6\% aporta una puntuación negativa a la categoría. "La habitación muy bonita" y "La decoración del hotel te hace sentir tranquilidad" son los ejemplos de comentarios encontrados.

\subsection{Ubicación}

Los comentarios que insertamos en esta categoría aclaran a los viajeros sobre la ubicación del hotel, su proximidad al transporte a Machu Picchu, su situación en el centro de la ciudad y la proximidad a espacios comerciales. Tiene una frecuencia del $42,4 \%$ y su naturaleza es marcadamente positiva, con $98,7 \%$ de las ocurrencias, mientras que la experiencia negativa tiene una sola ocurrencia (1.3\%). Registramos expresiones como: "Su ubicación es inmejorable", "El hotel está perfectamente ubicado, al lado del tren y de los buses" y "El hotel está bien localizado, cerca la estación de tren y el punto donde salen dos buses para Machu Picchu”.

\subsection{Precio}

Un comentario en esta categoría busca transmitir a los usuarios de Internet la experiencia del costo del alojamiento o la comida, mencionando si los precios son altos o no. Es una categoría con poca representación (solo 5 de 177 comentarios), dominada por comentarios positivos (80\%). Solo un huésped deja un mensaje negativo: "Los precios en el restaurante me parecieron muy elevados ... costoso".

\subsection{Costo-beneficio}

Esta categoría incluye comentarios que se refieren a una relación entre el servicio prestado y el precio cobrado, como se puede verificar en el comentario: "Costo beneficio, buen precio". Esta categoría muestra una ocurrencia baja: solo 8 comentarios (4,5\%). De estos, el $75 \%$ son positivos y solo el $25 \%$ hacen referencia a una mala experiencia. 


\subsection{Ofertas}

Los comentarios aluden a regalos, recuerdos, pequeños gestos que el hotel ha tenido hacia los huéspedes. Se menciona 27 veces $(15,3 \%)$ y no aparecen comentarios negativos. "Agua de cortesía", "En el lobby tienen té de coca o muña para ayudar con el mal de altura", "Te llevan las maletas al tren", "Ángela nos dio los burritos de regalo para la buena suerte", "Welcome drink", "Ofrecen pisco sour gratuito de bienvenida" y "Las amenidades en la habitación, de las mejores que hemos tenido".

\subsection{Spa}

Los comentarios en esta categoría se refieren a la impresión y las condiciones de acceso a este servicio. Es comentado sólo por 8 clientes $(4,5 \%)$ y siempre en un tono positivo. "El hotel cuenta también con servicio de spa, costoso, pero uno lo tiene si uno lo desea” o " $A$ Ahhhh y el pequeño spa merece la pena, el masaje fue muy relajante!".

\subsection{Ecología}

Entre los 177 comentarios que conforman la muestra de este estudio, 2 destacan las prácticas ambientales del hotel, una experiencia que los huéspedes y las unidades de alojamiento han valorado cada vez más: "Muchas empresas hoteleras hoy en día están implementando prácticas verdes simples y rentables, como reciclar, reutilizar la ropa de cama y reducir los residuos. Los gerentes y operadores de hoteles no son los únicos preocupados por las cuestiones medioambientales. A lo largo de los años, los huéspedes del hotel también se han vuelto cada vez más conscientes de estos problemas y de las prácticas ecológicas de los hoteles"8 (Yi et al., 2018, p. 191).

8. "Many hotel companies today are implementing simple and cost-effective green practices such as recycling, reusing linen, and reducing waste. Hotel managers and operators are not the only ones concerned about environmental issues. Over the years, hotel guests have also become increasingly aware of these issues and hotels' green practices" (texto original en inglés). 
Los dos comentarios son de naturaleza positiva, que indican más una realidad que la valoración de la misma: "Basa su propuesta en el consumo responsable y el cuidado del medio ambiente" y "Respeto por pautas ecológicas".

\section{Conclusiones}

Expresiones opuestas como "No volvería a venir ni lo recomendaría" y "Super recomendaría el lugar" pueden coexistir en la lista de comentarios para el mismo hotel. Tal disparidad deja al lector indeciso, pero ciertamente causará una impresión: el hotel no ha convencido a todos los que pasaron por allí. Ahora, al determinar la elección de un establecimiento determinado, el viajero preferirá el que tenga el mayor consenso y que tenga las mejores opiniones sobre ciertas experiencias de consumo. Independientemente de esto, es igualmente relevante en todo este proceso (aunque no es el objeto de observación en este trabajo) la existencia y la naturaleza de la respuesta que la persona responsable de la gestión de la comunicación online da a cada uno de los comentarios.

En nuestra muestra, el $87 \%$ de los huéspedes que escribieron sobre hoteles en la cadena de TripAdvisor, reafirman expresamente (después de enumerar y evaluar diferentes criterios) los 14 que formaron nuestra tabla de análisis. Cabe señalar que algunos de estos criterios aparecen en otros estudios que observan los motivos de satisfacción reportados en los comentarios en la misma red social (Bui, 2017; Li et al., 2013) o de insatisfacción (Dinçer \& Alrawadiesh, 2017).

Los resultados obtenidos nos llevan a responder una de las preguntas específicas que guían la investigación, a saber, si prevalecen los comentarios positivos o negativos. En ese sentido, predominan los primeros, como se puede concluir de la presentación de los resultados y, más esquemáticamente, de la comparación entre las Figuras 1 y 2. Asimismo, las experiencias más apreciadas por los viajeros (y descritas en nuestra muestra) fueron "servicio", con 133 comentarios; "comida", experiencia reportada 99 veces; "habitaciones", con 93 referencias y "ubicación”, con 74 menciones.

La imagen que obtenemos al leer los datos de la muestra es que el grupo hotelero en Machu Picchu valora un trato cuidadoso del huésped, de manera transversal, generalizado en varios hoteles, que contempla desde cómo se recibe al huésped al comienzo de su experiencia: los viajeros relatan (con sorpresa 
y satisfacción) el hecho de que un empleado determinado va a la estación de tren para llevarlos al hotel, cuidando sus maletas durante este proceso. Esta atenta recepción (antes de llegar al espacio físico del hotel) continúa con comentarios de atenciones, como la entrega de un recuerdo o una bebida, entre otros cuidados comentados por los huéspedes, quienes (casi en su totalidad) mencionan el esfuerzo físico de la visita a las ruinas de Machu Picchu, motivo del viaje y del alojamiento.

Con respecto al "servicio" (como un atributo de experiencia relevante) entran a tallar varias referencias de empleados, debido a su correcta presentación por sus nombres, razón de la prominencia y palabras de agradecimiento. Esta humanización es de gran riqueza y un fuerte diferencial en un sector en el que el proveedor de servicios forma parte, por lo que es aconsejable tener una fuerte conciencia y capacitación de los empleados de todos los hoteles para generalizar esta experiencia. Cabe señalar que este tipo de comentarios indica también que las empresas prestan atención a los factores clave para subir en su clasificación en TripAdvisor (ReviewPro, 2013).

Dichos comentarios están de acuerdo con la tesis de Craig (citado en Majó et al., 2018), quien explica que los viajeros comentan no sólo aspectos lujosos, sino pequeños detalles, lo inesperado y la atención que el personal del hotel les ofrece. Las apreciaciones de los visitantes son acordes con lo expresado por Liat et al.: "Los huéspedes consideran que la calidad del servicio también es uno de los factores más importantes de la satisfacción del cliente"" (citados en Bui, 2017, p. 8).

En el contexto de experiencias de servicio menos apreciadas, surgen reacciones ante los problemas que ocurren durante la estadía o la falta de respuesta a las solicitudes hechas en el momento de las reservas, lo que se extiende en los diferentes momentos del viaje: desde la planificación hasta la finalización de la misma. Ahora bien, estos comentarios pueden influir en aquellos que prestan más atención a los detalles de planificación y los contactos a distancia necesarios o convenientes, teniendo que ser objeto de una mejor atención al momento de darles una respuesta que pueda aliviar el problema informado.

\footnotetext{
9. "Guests consider service quality too be one of the most important factors of customer satisfaction" (texto original en inglés).
} 
Cuando hay un gran esfuerzo físico por delante, es importante que la persona se alimente bien y esté preparada para enfrentar el desafío: la respuesta positiva a esta necesidad es parte de la reputación online de los hoteles en la región, comentada, sobre todo, en la calidad y cantidad del desayuno o las "comidas".

Asociados a estos, se encontraron varios comentarios sobre la conveniencia de los horarios de atención del servicio desde el amanecer, satisfaciendo la convivencia de aquellos que tienen que irse muy temprano para disfrutar de un paseo. Así, el hecho de ajustar la oferta para aumentar la notoriedad de un hotel determinado también implica leer las evaluaciones que los huéspedes hacen de lo que la competencia ofrece, lo que nos lleva a una ventaja de los comentarios online para las empresas.

La tercera experiencia más comentada es la de las "habitaciones" (60\% de la muestra). Al no ser evaluado por la abrumadora mayoría de los clientes, a diferencia de otros estudios (Bui, 2017; Li et al., 2013), la hora y el lugar del sueño es un parámetro prominente, especialmente en sus detalles. Si los comentarios positivos giran en torno a denominadores comunes (como el tamaño de las camas y la comodidad de las almohadas que se repiten en la muestra en su conjunto) son detalles aislados que configuran la naturaleza de los comentarios negativos. Así, dichos comentarios tienden a elaborarse como una narración breve sobre un tema, en el que el cliente detalla secuencias ilustrativas y justificaciones para desilusionarse o romper sus propias expectativas.

La "ubicación" es la cuarta experiencia más reportada y la imagen que proviene de estos comentarios es que los hoteles de Machu Picchu ofrecen una ubicación privilegiada para acceder al destino que impulsa estos viajes. Esta es la idea transmitida en el 98,7\% de los casos. La evaluación de la ubicación se basa en la proximidad de los medios de transporte (autobuses y trenes) que aseguran el viaje a Machu Picchu y la centralidad del hotel, es decir, su vecindario poblado por establecimientos comerciales y servicios útiles durante la estadía en esos espacios.

Si bien aparecieron otras experiencias, como hemos visto en la muestra analizada, se destacan las cuatro anteriores, ya que son significativas cuando se trata de evaluar la imagen de las unidades hoteleras y proporcionar pistas relevantes por las cuales los gerentes de los hoteles pueden guiarse para cumplir con las expectativas de los clientes actuales. 
Desde nuestro punto de vista, las empresas requieren una actitud de atención y escucha permanente del consumidor, a fin de crear ofertas relevantes y comunicarlas, manteniendo la atención del visitante en este universo competitivo online. En resumen, se trata de trabajar para construir una reputación online que sea favorable para ellos y les brinde ventajas comerciales. Sin olvidar los intereses del consumidor. Así, el conjunto de comentarios online sobre las marcas de hoteles es una guía para la toma de decisiones en diferentes momentos del proceso y la impresión global de su reputación online, una guía útil en un momento en que la confianza recae más en el e-WOM que sobre los discursos que emanan de las propias empresas (Dinçer \& Alrawadieh, 2017; Galhardo, 2017; Galhardo et al., 2017; Lei et al., 2015; Li et al., 2013).

Del estudio también concluimos que el análisis de contenido permite observar la verdadera experiencia de los viajeros que se refleja en los comentarios online, como lo respaldan Li et al. (2013), apareciendo así como una técnica de investigación relevante para futuras investigaciones que tienen como objetivo evaluar los principales aspectos a los que los clientes de hoteles u otras empresas del sector turístico prestan más o menos atención y que, como ya se mencionó, son información invaluable para los gerentes de las empresas.

Consideramos que el objetivo general, planteado al inicio de esta investigación, se logró en gran medida, ya que pudimos identificar los 14 atributos principales comentados por los clientes, así como verificar que, en su mayor parte, estos comentarios son positivos.

El presente trabajo contiene dos límites principales que pueden superarse en futuras investigaciones. Por un lado, el proceso de revisión empleado no empleó un programa informático, el cual permitiría una investigación a mayor escala. Por otro lado, sólo se tomó en cuenta los comentarios en español. La consideración de otros idiomas (como el inglés o el portugués) podría aportar otras ideas para futuros estudios $\mathrm{y}$, eventualmente, conclusiones distintas. 


\section{Fuentes consultadas}

Bui, H. (2017). Exploring the relationship between the cultural backgrounds of hotel guests and their satisfaction of hotel attributes via a content analysis of Tripadvisor reviews [Tesis de bachillerato, School of Tourism]. Bournemouth University.

Cohen, J., \& Olsen, K. (2013). The impacts of complementary information technology resources on the service-profit chain and competitive performance of South African hospitality firms. International Journal of Hospitality Management, 4, 245-254. https://doi.org/10.1016/j. ijhm.2013.04.005

Crespo, G., \& Vega, J. (2018). Criterios para responder quejas en Tripadvisor: caso Hotel Wyndham Costa del Sol Lima Airport - Periodo 2012-2016. [Tesis de bachillerato, Facultad de Administración Hotelera, Turismo y Gastronomía]. Universidad San Ignacio de Loyola. http://repositorio.usil.edu.pe/bitstream/USIL/3199/3/2018_Vega-Oca\%c3\%b1a.pdf

Cunningham, P., Smyth, B., Wu, G., \& Greene, D. (2010). Does TripAdvisor Makes Hotels Better? [Reporte técnico]. School of Computer Science \& Informatics, University College Dublin

Diana-Jens, P., \& Rodríguez Ruibal, A. (2015). La reputación online y su impacto en la política de precios de los hoteles. Cuadernos de Turismo, 36, 129-155. https://doi.org/10.6018/turismo.36.230911

Dinçer, M., \& Alrawadieh, Z. (2017). Negative Word of Mouse in the Hotel Industry: A Content Analysis of Online Reviews on Luxury Hotels in Jordan. Journal of Hospitality Marketing and Management, 26(8), 785-804. https://doi.org/10.1080/19368623.2017.1320258

Flores, J., \& Tijero, J. (2017). Influencia de sitio web tripadvisor en la demanda turística de hoteles de 3 estrellas del centro histórico del Cusco [Tesis de bachillerato, Escuela Profesional de Turismo, Facultad de Ciencias y Humanidades]. Universidad Andina del Cusco. 
Galhardo, A. (2017). O website dos estabelecimentos hoteleiros de São Tomé e Príncipe: variáveis de comunicação e de interação. En M. Ledo et al. (Eds.)., Atas no I Congresso Internacional da Asociación galega de investigadores e investigadoras en comunicación. Alén de fonteras: redes na diversidade (pp. 367-384). Universidade de Santiago de Compostela.

Galhardo, A., Paupério, B., \& Moutinho, A. (2017). Comunicação, redes sociais e hotelaria: o Facebook dos "hostels" da cidade do Porto. En Atas dos Dias da Investigação na UFP Research Days Proceedings 2017 [eBook]. Gabinete de Relações Internacionais e Apoio ao Desenvolvimento Institucional; Universidade Fernando Pessoa.

Gretzel, U., \& Yoo, K. (2008). Use and impact of online travel reviews. En P. O'Connor, W. Höpken, W. \& U. Gretzel, Information and Communication Technologies in Tourism 2008: Proceedings of the International Conference in Innsbruck, Austria, 2008 (pp. 35-46). https://www. researchgate.net/publication/221357282_Use_and_Impact_of_Online_Travel_Reviews

Lakatos, M., \& Marconi, A. (2007). Técnicas de pesquisa. Atlas.

Lei, S., \& Law, R. (2015). Content Analysis of Tripadvisor Reviews on Restaurants: a case of study of Macau. Journal of Tourism, XVI(1), 17-28. http://agrilife.org/ertr/files/2015/02/SP03_ReviewSession_Lei.pdf

Li, H., Ye, Q., \& Law, R. (2013). Determinants of Customer Satisfaction in the Hotel Industry: An Application of Online Review Analysis. Asia Pacific Journal of Tourism Research, 18(7), 784-802. https://doi.org/1 0.1080/10941665.2012.708351

Li, X., Wang, Y., \& Yu, Y. (2015). Present and future hotel website marketing activities: Change propensity analysis. International Journal of Hospitality Management, 47, 131-139. https://doi.org/10.1016/j. ijhm.2015.02.007

Majó, J., Moya, D., \& Vall-1losera, L. (2018). Impacto de las redes sociales en los ingresos de los hoteles en Colombia, Ecuador y Perú. Revista Facultad de Ciencias Económicas, XXVI (1), https://doi.org/10.18359/rfce.3143 
Núñez-Melgar-Molinari, C. (2016). Sin perder el cable a tierra: la identidad del viajero y su interacción en el mundo virtual [Trabajo de investigación para optar la Licenciatura en Comunicación]. Universidad de Lima. http://repositorio.ulima.edu.pe/handle/ulima/2987

ReviewPro. (2013). Guía. Las 8 claves para mejorar tu ranking en TripAdvisor. https://www.reviewpro.com/es/guia-estrategias-para-mejorar-ranking-tripadvisor-thanks/

Senecal, S., \& Nantel, J. (2004). The influence of online product recommendations on consumers' online choices. Journal of Retailing, 80(2), 159-169.

Sparks, B., \& Browning, V. (2011). The impact of online reviews on hotel booking intentions and perception of trust. Tourism Management, 32(6), 1310-1323. https://doi.org/10.1016/j.tourman.2010.12.011

TripAdvisor. (2020). Sala de prensa. Información acerca de TripAdvisor. https://tripadvisor.mediaroom.com/es-about-us

Willemsen, L., Neijens, P., Bronner, F., \& De Ridder, J. (2011). "Highly recommended!" the content characteristics and perceived usefulness of online consumer reviews. Journal of Computer-Mediated Communication. 17(1), 19-38. https://doi.org/10.1111/j.1083-6101.2011.01551.x

Yi, S., Li, X., \& Jai, T. (2018). Hotel guest's perception of best green pratices: A content analysis of online reviews. Tourism and Hospitality Research, 18(2), 191-202. https://doi.org/10.1177/1467358416637251

Zanibellato, F., Rosin, V., \& Casarin, F. (2018). How the attributes of a museum experience influence electronic Word-of-Mouth Valence: an analysis of online museum reviews. International Journal of Arts Management, 21(1), 76-90. https://eds.b.ebscohost.com/eds/pdfviewer/pdfviewer?vid=3\&sid=6370a6a0-87c4-40bd-a28c-0dad9536ff9a $\% 40$ pdc-v-sessmgr04 